\title{
Pet Business Opportunities and Sharing Economy in the Post-Covid-19 Pandemic Era
}

\author{
Tsai, Shieunt-Han ${ }^{1 *}$ \\ ${ }^{1}$ Department of Sports, Health, and Leisure, Kun Shan University, Tainan, 710303, Taiwan \\ *Corresponding Author. Email: shieunt@gmail.com
}

\begin{abstract}
The number of Americans adopting pets has increased, as if the pandemic crisis has strengthened the people's need for pet companionship. As the post-pandemic era is approaching, there are 140,000 Taiwanese participating in Taipei Pet Products Show. It reveals that the markets of pet food, appliances, and health food are flourishing and a lot of families cherish pets more than they did in the pre-pandemic stage. Furthermore, Taiwanese pet-beauty shop and pet-veterinary clinic are still providing services separately. The market does not seem to have a similar network platform for pets and masters in the stage. As an entrepreneur who loves pet, I hope the government can provide an integrated network platform and quality services for Taiwanese petmasters, just like Uber and Airbnb, which encourage all shops to serve their proper purposes.
\end{abstract}

Keywords: sharing economy, pet business opportunity, service marketing, post-Covid-19 pandemic

\section{INTRODUCTION}

The world has been blocked because of the period of Covid19 pandemic. People cannot travel freely, and even pets cannot move either. As the post-pandemic era is approaching, we want to provide our pets with a safer and healthier living environment than usual. According to the estimation of Biotech Industry Research Center from Taiwan Institute of Economic Research, the birth-rate of pets may surpass the national birth-rate in 2020, and the number of pets will exceed the number of children to reach the Golden Cross. In that case, the number of pets may reach 2.8 million, which is larger than the number of children under 15 years old in Taiwan in 2020 [1]. Furthermore, the domestic pet food market size was NT \$25 billion in 2020, with a production value of NT $\$ 50$ billion [2].

Besides, we found out that vigorous development of the petcare industry is due to the change in the concept of pets in Taiwan. From the early days of only owning pets, it gradually changed to resemble the desire of European and American owners to establish a closer relationship with pets. It can be seen that the change in family structure has changed the status of pets in the family, and the companionship of them has become our spiritual support, healing our hearts and minds, while the global sharing economy has brought about the explosion of business opportunities for pets and the expansion of creative ideas in service marketing. For the reason, [3] has formed a network platform of pet services that masters need which is a fresh idea of pet-service entrepreneurship in America.

\section{BACKGROUND}

Pets are just like our family members, and they will also have a life of being old and sick. We are fortunate to be accompanied by them, and we also need to care for their physical and mental health. In addition to the scope of the veterinary field, the rest will be the scope of services that this venture can provide to pets and their owners with modest marketing.

Accordingly, this paper explores this pet integration platform in three aspects, hoping to explore the feasibility and future development of the pet platform initially through the relevant questionnaire.

\subsection{Sharing Economy}

The sharing economy is the way society works for the sharing of human beings and resources, including the creation, production, distribution, trade and consumption of goods and services by different individuals and organizations. People rent the resources they own for a fee to others, making more efficient use of idle resources and thus making the overall use of resources more efficient. Common forms include car, public bicycle, and mobile power sharing, as well as the exchange of accommodation, which has the effect of weakening ownership and strengthening usage rights [4].

The sharing economy is divided into $\mathrm{C} 2 \mathrm{C}$ such as Uber and Airbnb, and B2C such as Wework and Netjets. Currently a variety of industries are joining including carpooling, lawyers, rooms, cars, home cooks, catering, electric 
scooters, bicycles, private jets, and offices. More industries are expected to be added in the future to make it more convenient for non-owners.

Uber is a transportation network company headquartered in the U.S. that develops mobile apps to connect passengers and drivers, offering passenger car rentals, and mediasharing in the sharing economy. Passengers can book these passenger-carrying vehicles by sending a text message or using a mobile-app to access the platform, and the mobileapp can track the vehicle's location. The company operates in 785 metropolitan areas worldwide, with 110 million users worldwide and a $69 \%$ market share in the United States [5]. Airbnb is a website that allows public to rent out accommodation in B\&Bs, offering short-term rentals of houses or rooms. Enabling travelers to discover and book a variety of unique listings around the world through a website or mobile phone, the company is headquartered in the United States and operates under the management of Airbnb, Inc. Currently, Airbnb has over 3,000,000 listings in 191 countries and 65,000 cities. Users of the website must register and create an Internet account. Each accommodation is linked to a landlord whose profile includes recommendations from other users, reviews from customers who have stayed, as well as responses to ratings and private message systems.

Asia's Grab Enterprises, which came to Uber for its Southeast Asia acquisition in 2018, may currently be affected by Uber and Lyft operating conditions, but is expected to come out of Uber's shadow in the future [6].

\subsection{Business Opportunities for Pets}

The pet market in the United States is affected by the COVID-19 pandemic, which may last for several years after the crisis. The sales of the entire pet market will remain stable, and the sales decline of the pet service department will be offset by the sales growth of the pet products department by 2020. Despite of being affected by the COVID-19 pandemic, retail sales of pet food and non-food pet supplies will grow in 2020, while the veterinary services industry will return to 2019 income levels in 2021 and 2022. Non-medical pet-care expected service income will also recover [7].

The global pet supplies market is forecasted to grow at a compound annual growth-rate of $7 \%$ and reach USD 11.64 billion between 2020 and 2024. Technological development and the expansion of product portfolio to achieve high product quality are the key factors driving the growth of this market [8].

According to Tsai and Tian [9], there are more than 6,000 small pet hospitals, beauty salons, and other pet retail channels in Taiwan, and these physical stores lack the integration to meet their operational needs and integration benefits. If a new type of supply chain model for pet products can be established, a business and overall supply chain operation model can be formed, and a channel alliance can be formed by integrating the small pet medical and aesthetic channels, so that in addition to their own grooming and medical professions, they can obtain more diversified products at a lower cost and increase their sales performance. This is the source of this venture's business ideas.

$\mathrm{Lu}[10]$ found that global pet consumption is on a significant upward trend, with more than 43.14 million people in the U.S. owning pet dogs, for a total of more than 61.53 million; and 31 million households in the U.S. have at least one cat, for a total of more than 74.89 million domesticated cats, out of a total of 120 million households. This condition shows that a new pet service model with Internet, community, professional, and quality services has taken shape.

Chen [11] studied the proportion of dogs and cats in each county and city. The number of dogs and cats in the six capitals accounted for $65 \%$, and two-thirds of pet food retailers in Taiwan gathered in the six capitals, indicates high spending power in the metropolitan area. When "pets become children and owners become parents", people care more about their pets' healthy diet, recreation, physical and spiritual care, educational programs, and even funeral arrangements afterward.

Pet services continue to evolve. For example, pet grooming is no longer limited to bathing and styling services, but even extends to spa honors with medical effects; when masters go abroad, they board their children in pet hotels that offer 24-hour APP remote monitoring services; many owners listen to their children's voices through pet communicators in order to get to know them better; and insurance companies are also looking at the medical needs of pets and have launched pet-related insurance solutions, which also have market potential in the future. By fully capturing the "companionship" needs of pet parents, we are able to capitalize on the more than $\$ 50$ billion pet-market opportunity in Taiwan [12].

\subsection{Marketing of Services}

American service marketers Booms and Bitner [13] have proposed a 7P service marketing-mix strategy. Those 7Ps include product, price, promotion (e.g., the homepage of a website in China, advertises only $\$ 100$ per day, allowing the brand to gain strong exposure and awareness on its home and news pages; or buying keywords to strongly drive-up the number of searches and awareness), channels, people, physical displays (e.g., mobile phones, luxury homes), and service processes (the time-consuming process of fully capturing the process from service delivery to customer), as presented in Table 1. 
Table 1 Service Marketing 7Ps

\begin{tabular}{|c|c|}
\hline Strategy & Contents \\
\hline Product & Quality, features, brand, service items, guarantee, after-sales service \\
\hline Price & Discounts, payment terms, customers' perceived value, price, differentiation \\
\hline Passageway & Location, accessibility, distribution channels, distribution scope \\
\hline Promotion & Advertising, marketing staff, publicity, public relations, image promotion, promotion \\
\hline Staff & Attitude and behavior, reliability, accountability, communication, customer engagement \\
\hline Physical Display & Environmental design, equipment and facilities \\
\hline Process & Employee discretion, event flow, customer engagement \\
\hline
\end{tabular}

Table 2 Demographic Profile of the Respondents ( $N=100)$

\begin{tabular}{|c|c|c|c|}
\hline & & Number of People & Percentage \\
\hline \multirow{3}{*}{ Occupation } & Commuter & 44 & $44 \%$ \\
\hline & Housekeeper & 15 & $15 \%$ \\
\hline & Student & 41 & $41 \%$ \\
\hline \multirow{4}{*}{ Average Monthly Salary } & Below 23,100 & 16 & $16 \%$ \\
\hline & $23,100-30,000$ & 64 & $64 \%$ \\
\hline & $30,001-35,000$ & 18 & $18 \%$ \\
\hline & Above 35,001 & 2 & $2 \%$ \\
\hline \multirow{3}{*}{ Keeping Pets } & Yes & 65 & $65 \%$ \\
\hline & No & 7 & $7 \%$ \\
\hline & Want to & 28 & $28 \%$ \\
\hline \multirow[t]{5}{*}{ Average monthly expenditure on pets } & Below 1,000 & 5 & $5 \%$ \\
\hline & $1,001-2,000$ & 30 & $30 \%$ \\
\hline & $2,001-3,000$ & 58 & $58 \%$ \\
\hline & $3,001-4,000$ & 5 & $5 \%$ \\
\hline & Above 4,001 & 2 & $2 \%$ \\
\hline \multirow{5}{*}{$\begin{array}{l}\text { How they find out about pet supplies (multiple } \\
\text { selection accepted) }\end{array}$} & Friends and Relatives & 71 & $25.83 \%$ \\
\hline & Internet & 66 & $24 \%$ \\
\hline & Advertisements & 49 & $17.83 \%$ \\
\hline & Store Popularity & 68 & $24.73 \%$ \\
\hline & Pass by & 21 & $7.61 \%$ \\
\hline \multirow{3}{*}{ Where they usually buy pet supplies } & Physical Store & 30 & $30 \%$ \\
\hline & Internet Shopping & 39 & $39 \%$ \\
\hline & Both & 34 & $34 \%$ \\
\hline \multirow{3}{*}{$\begin{array}{l}\text { Where they take their pet for grooming/ bathing } \\
\text { during the week }\end{array}$} & Near Home & 63 & $63 \%$ \\
\hline & Famous Store & 15 & $15 \%$ \\
\hline & Anywhere Convenient & 22 & $22 \%$ \\
\hline \multirow{4}{*}{$\begin{array}{l}\text { Frequency of taking pets for bathing and } \\
\text { grooming }\end{array}$} & Once a Week & 4 & $4 \%$ \\
\hline & Once a Month & 26 & $26 \%$ \\
\hline & Twice or More in a Month & 0 & $0 \%$ \\
\hline & Only on Special Occasions & 70 & $70 \%$ \\
\hline \multirow{5}{*}{ Daily time with your pet } & $1-2$ Hours & 5 & $5 \%$ \\
\hline & $2-3$ Hours & 13 & $13 \%$ \\
\hline & More than 3 Hours & 65 & $65 \%$ \\
\hline & Only on Weekends & 17 & $17 \%$ \\
\hline & Usually Cannot & 0 & $0 \%$ \\
\hline
\end{tabular}




\begin{tabular}{|l|l|c|c|}
\hline $\begin{array}{l}\text { Willingness to use websites that provide } \\
\text { information on pet supplies / pet grooming } \\
\text { locations }\end{array}$ & Willing & 95 & $95 \%$ \\
\cline { 2 - 4 } $\begin{array}{l}\text { You would recommend this site to your friends } \\
\text { and family }\end{array}$ & Unwilling & 5 & $5 \%$ \\
\hline \multirow{3}{*}{$\begin{array}{l}\text { You are reluctant to use this site for the following } \\
\text { reasons (multiple selections accepted) }\end{array}$} & Yes & 100 & $100 \%$ \\
\cline { 2 - 4 } & No & 0 & $0 \%$ \\
\cline { 2 - 4 } & No Internet & 2 & $38.92 \%$ \\
\cline { 2 - 4 } & Not Practical & 10 & $6.19 \%$ \\
\hline \multirow{4}{*}{$\begin{array}{l}\text { Are they willing to pay to join the network so you } \\
\text { can enjoy the following discounts }\end{array}$} & 1,099 & 38 & $53.89 \%$ \\
\cline { 2 - 4 } & 1,299 & 0 & $38 \%$ \\
\cline { 2 - 4 } & 1,599 & 0 & $0 \%$ \\
\cline { 2 - 4 } & 1,999 & 62 & $0 \%$ \\
\hline
\end{tabular}

Table 3 Willingness to use the services of this platform $(\mathrm{N}=100)$

\begin{tabular}{|l|c|c|c|}
\hline \multicolumn{2}{|c|}{} & Number & Percentage \\
\hline Are you willing to pay the membership fee to enjoy free door-to-door delivery & Yes & 86 & $86 \%$ \\
\cline { 2 - 4 } of carefully selected pet products & No & 14 & $14 \%$ \\
\hline \multirow{2}{*}{ Are you willing to experiment with the platform } & Yes & 98 & $98 \%$ \\
\cline { 2 - 4 } & No & 2 & $2 \%$ \\
\hline Are you willing to try pet-transport related websites & Yes & 85 & $85 \%$ \\
\cline { 2 - 4 } & No & 15 & $15 \%$ \\
\hline Are you willing to use this website without time limit for your pet & Yes & 95 & $95 \%$ \\
\cline { 2 - 4 } & No & 5 & $5 \%$ \\
\hline Are you willing to purchase supplies / merchandise needed for pets on this & Yes & 97 & $97 \%$ \\
\cline { 2 - 4 } website & No & 3 & $3 \%$ \\
\hline Are you willing to purchase pet insurance on this website & Yes & 21 & $21 \%$ \\
\cline { 2 - 4 } & No & 79 & $79 \%$ \\
\hline Are you willing to use a point card in exchange for a gift or to use a roll & Yes & 95 & $95 \%$ \\
\cline { 2 - 4 } & No & 5 & $5 \%$ \\
\hline Are you willing to pay for the production of a pet memorial gift on this website & Yes & 91 & $91 \%$ \\
\cline { 2 - 4 } & No & 9 & $9 \%$ \\
\hline If there is a site like this one, are you willing to use it & Yes & 96 & $96 \%$ \\
\cline { 2 - 4 } & No & 4 & $4 \%$ \\
\hline
\end{tabular}

\subsection{Online Shopping}

Online shopping has become one of the habits of modern people to purchase daily necessities. According to the statistics from Taiwan Ministry of Economic Affairs, the turnover of the e-shopping industry has been increasing year by year. In 2017, it was about NT $\$ 170$ billion, with an average annual growth-rate of $7.2 \%$ in the past three years. Trends and Deriving Insights, a Taiwan management consulting firm, predicts that online shopping opportunities in 2020 will exceed NT $\$ 200$ billion.

At the same time, Taiwan Ministry of the Interior announced that the birth population in 2018 was the second lowest in history (the crude birth-rate was only $7.56 \%$ ), and 
the marriage-rate also hit a 9-year low. Trends and Deriving Insights estimates that the gross birth of pet will reach about 2.8 million in 2020, which exceeding 15 percent of birth of newborn baby for the first time. With the increasing popularity of online shopping, the online shopping market for pet-food products will have the opportunity to grow substantially.

Taking South Korea as an example, one-third (32\%) of petfood revenue comes from online shopping. Trends and Deriving Insights predicts that online pet-food shopping in Taiwan will account for a quarter $(23 \%)$ of the overall petfood market revenue. Looking at 6 billion business opportunities in 2020 , it is expected to become the next unicorn in online shopping!

According to the Trends and Deriving Insights survey, about half of the expenses related to furry children are allocated on feed. It is estimated that at least 25 billion yuan in food-business opportunities, coupled with the fact that food and health are closely related, the feed market has a greater opportunity for consumption upgrade. They believe that e-commerce and the related industries should target pet-food business opportunities and increase the incentives for parents to buy for increasing customers' stickiness and customers' unit price.

There are two-thirds (65\%) of pets' parents share related messages on social media at least twice a week. Trends and Deriving Insights recommends that manufacturers target pet parents of different generations, through different social platforms, use online word-of-mouth sharing and design graphics to tell stories, exert the influence of social media, and convert them into consumer money flow.

To suggest that, the research and development of multifunctional smart products that integrate network technology, will also be a key business opportunity for pets. Observing that smart cat litter boxes, pet heating and cooling nests, circulating water machines, feeders, interactive toys, etc., have been launched in the market, the common points of these products do not only emphasize the aesthetic refinement and multi-function intelligence, but also allow the masters to accompany and care their pets anytime and anywhere [14].

\subsection{Research Methodology}

In order to understand the acceptance of similar integratedcare service platforms among pet owners in China before starting their own business, this paper uses a literature collection method and a quantitative questionnaire to obtain the necessary research results to facilitate the future business start-up. Human and financial resources are still being sought, such as participation in the entrepreneurial competitions held by schools and organizations to facilitate fund raising.

In the future, there are opportunities to apply for fundraising such as the Executive Yuan's New Dream Network or the Executive Yuan's National Development Association Angel Fund to provide more caring and comprehensive services for families with pets. We will first test the initial acceptance of the integration platform by pet families, and then correct the customer satisfaction, service offerings, and integration channels.

The pre-test used Google to conduct a web-based survey, which is divided into two parts, the first part is basic information and personal consumption behavior, and the second part is the use of the service on this platform. This survey was conducted from August 1, 2019 to November 30, 2019 and 100 copies were collected.

\subsubsection{Basic Information and Personal Consumption Behavior}

Most of the respondents in this survey were students; the average monthly income of the respondents ranged from $\$ 23,100$ to $\$ 30,000$; most of the respondents had pets; the average monthly expenditure on pets ranged from $\$ 2,001$ to $\$ 3,000$; most of the information on pet products came from referrals from friends and relatives, internet inquiries and store popularity; most people are reluctant to use this website due to the lack of popularity, and most people are unwilling to spend money to join the online membership.

Therefore, at the beginning of the fundraising period, the company may start to release advertisements and use a large number of ads to attract customers' attention, input and transactions to consume this platform, as shown in Table 2 .

\subsubsection{The Use of Services on the Platform}

The results of this survey are a boost to the confidence of the entrepreneurs, with a high percentage of positive messages. For example, most people who are willing to try the pet pick-up and drop-off website and use the platform, are willing to use and purchase the solutions provided by the platform. In addition to the fact that $79 \%$ of people are reluctant to buy pet insurance on the platform, it is probably because the consumers have their own insurance agent, thus the relevant pet insurance can be purchased directly from the insurance industry.

Although consumers are not yet convinced by this venture, we are confident that consumers will be willing to buy in the future, because people will get used to the integration of the platform, just like they would if they went shopping in Allianz, they will get used to spending together. It is hoped that this venture will be the life of the relevant entrepreneurs, and the passive income generated will create a happy life for everyone, as shown in Table 3.

\section{CONCLUSION}

The last decade has been the most rapid time for technology to evolve - Hadoop (collecting big data), Github (code escrow), and cloud servers (without the need for a big server room) have all emerged at this time, and like the perfect business model, there needs to be the technology to go along 
with it, and start-ups are at this best time to build platforms to leverage these technologies to rapidly evolve.

In addition to this phenomenon, consumers are also accustomed to smartphones, online shopping and evaluation systems, and social networks, indicating that consumers are ready to face this information generation [15], which is really a good time to explore all kinds of idle resources and business resources.

The sharing economy has emerged as a result of technology and creative ideas in modern society. Coupled with the changing family structure in East Asia, the pet industry has boomed. In addition to providing better and more convenient services to pets and their owners, it also enhances the profitability of pet grooming, health and foodrelated businesses.

The following business model of Airbnb has been compiled according to Wei [16], which is a reference for the operation of this venture:

1. Target Customer Tier: The "Bilateral Platform" Model.

2. Value proposition: Become a "home" for travelers in different cities and earn extra income by renting space.

3. Access: Web-based.

4. Customer Relationship: We operate a community of "renters" to share our experiences with each other, enhance our service capabilities, and explore new products and services from them.

5. Revenue stream: Both tiers pay a fee in order to maintain platform profits

6. Key-resources: Brand power and a solid community to gain the support of many investors.

7. Key-activities: Digging into demand through the community, developing new products.

8. Key-partners: Third-party payment companies like PayPal and credit card companies work together to provide a convenient payment pipeline. Photographers can also increase business turnover.

9. Cost structure: The cost of marketing, research and development, and other units' sales partnerships.

With the aim of serving pet owners, we hope to integrate this new platform with technology and consumer habits, in order to have a smooth business process and successful results. In the future, we will continue to plan the following entrepreneurial elements, such as estimated sales performance, cost and profitability, as well as the design of store name, logo, company organization, service flow, online community, and advertising design, etc., to be launched on the platform's mobile-board and computerversion.

Once the fund has been raised, it will be a practical implementation of the entrepreneurial vision, and will also fulfill the service consumers' wish. We hope to make more pets and their masters more convenient and happier.

In these rapidly changing market conditions, if the company is well positioned to operate in the future, it may consider be changing from a partnership to a company limited by shares, or even expanding its operations with an eye to the international market

Besides, the change in the concept of pets turns out to be a vigorous development of the pet-care industry in Taiwan. From the early days of only owning pets, it gradually changed to resemble the desire of European and American owners to establish a closer relationship with pets. This change has also prompted the emergence of many new products in the Taiwanese market, such as high-tech "microchip feeders", "sniffing pads" that allow dogs to find hidden snacks, as well as some emerging services and occupations such as pet behavior counseling, pet photography, pet massage, pet hotel, and personal pet care. Recently popular in Taiwan are "pet communicators" who claim to be able to communicate with pets, which communicate their ideas to their owners.

We want to know more about what dog and cat are thinking. A Taiwanese firm, Pet Buddy, dedicated to improving cat behavior and enhancing the relationship between customers and cats after finding the certification program initiated by the International Association of Animal Behavior Consultants in the United States and obtaining the certification of "feline behavior consultant".

Not only that, massage can reduce pet stress and what matters is the happiness of pets. Many customers have older pets, which are inconvenient to move due to tight hind limb muscles. Some pet masseurs even serve hamsters or other small pets. Some customers are mainly from high-income groups and usually have no children. They care about the comfort and happiness of pets, not just providing pets with a place to sleep and eat [17].

These are good news for our company in the future, so that our platform services can be more diversified and attract more customers. Hopefully our company can run well for serving more pets and customers in the future.

\section{REFERENCES}

[1] J.J. Chen, 2020 Golden cross, Taiwan's pets exceed the number of children for the first time, Expert in Identifying Trends \& Deriving Insights, 2020. DOI: http://www.trendsightinc.com/insight $/ 2020 \%$ E9\%BB\% $83 \%$ E9\%87\%91\%Е4\%BA\%A4\%Е5\%8F\%89\%ЕF\%B C\%8C\%Е5\%8F\%B0\%Е7\%81\%А $3 \%$ Е8\%B2\%93\%Е7 $\% 8 \mathrm{~B} \% 97 \% \mathrm{E} 6 \% 95 \% \mathrm{~B} 8 \% \mathrm{E} 9 \% \mathrm{~A} 6 \% 96 \% \mathrm{E} 6 \% \mathrm{AC} \% \mathrm{~A} 1 \%$ Е8\%В6\%85\%Е9\%81\%8Е\%Е5\%85\%92\%Е7\%АВ\%А5 /

[2] S. W. Wu, Pets' economy is booming, Liberty Times Net, 2020. DOI: https://news.ltn.com.tw/news/lifeweekly/paper/1207392

[3] C. U. Kao, 2017, Airbnb for pets! The 27-year-old founder builds a company with a market value of 300 million US dollars by integrating "dog nanny" 
resources, Digital Age, DOI: https://www.bnext.com. tw/article/47396/rover.com-startup-philip-kimmey-petscare

[4] Sharing economy, 2020. Wikipedia,

DOI:https://en.wikipedia.org/wiki/Sharing_economy.

[5] Uber, 2020, Wikipedia,

DOI:https://zh.wikipedia.org/wiki/\%E5\%84\%AA\%E6 $\%$ AD\%A5

[6] U.S. Pet Outlook, 2020-2021: The COVID-19 impact, Packaged Facts, 2020. DOI:

https://www.giichinese.com.tw/report/pf944255-us-petmarket-outlook-covid-19-impact-june-update.html

[7] Airbnb, Wikipedia, 2020,

DOI:https://zh.wikipedia.org/zh-

tw/\%E7\%88\%B1\%E5\%BD\%BC\%E8\%BF\%8E

[8] Z. Y. Yu, Furkids Economics, Commercial Weekly, 2018,

DOI:https://www.businessweekly.com.tw/magazine/Art icle_page.aspx?id=36007

[9] L.C. Tsai, \& U. P. Tien, Taiwan pet market supply chain status and development, Logistics technology and strategy, 2012,

DOI:https://www.logisticnet.com.tw/newsCaseRunDeta il.asp?id=176.

[10] L. C. Lu, Analysis of China's pet market scale and investment opportunities, Forward-Looking Economist, 2016, DOI:www.qianzhan.com

[11] Z. Z. Chen, Furkids, the new market trending of Taiwan's economy, Current Business, 2018, DOI:www.trendingsightinc.com

[12] PetSmart website, 2020, DOI:

https://services.petsmart.com/

[13] B. Booms, M. Bitner, The Marketing Theory of 7Ps Global Professional Chinese Economic

Management Encyclopedia, 1981, DOI:

https://wiki.mbalib.com/zh-

tw/7Ps\%E8\%90\%A5\%E9\%94\%80\%E7\%90\%86\%E8

$\% \mathrm{AE} \% \mathrm{BA}$

[14] http://www.trendsightinc.com/insight/2020\% Е9\%9B\%BB\%Е5\%95\%86\%Е7\%87\%9F\%Е6\%94\%B6 \%Е4\%B8\%8А\%Е7\%9C\%8B2000\%Е5\%84\%84\%ЕF\% BC\%8E\%E5\%AF\%B5\%E5\%85\%92\%E5\%95\%86\%E5 $\% 93 \% 81 \% \mathrm{E} 6 \% 98 \%$ AF\% $4 \%$ B8\%8B\%Е4\%B $\% \% 80 \%$ Е5\%80\%8B\%Е7\%B6\%B2\%Е8\%B3\%BC\%E7\%8D\% A8/
[15] Danny, What is the sharing economy? How did it develop? Pocket economy, 2017,

DOI:www.pocketmoney.tw/sharing-economy

[16] W. S. Wei, A Business model diagram tells you how Airbnb is getting bigger and bigger! Manager, 2015, DOI:

www.managertoday.com.tw/articles/view/51464

[17] https://topics.amcham.com.tw/2020/06/\%E8\%93\%

$\mathrm{AC} \% \mathrm{E} 5 \% 8 \mathrm{~B} \% 83 \% \mathrm{E} 7 \% 99 \% \mathrm{BC} \% \mathrm{E} 5 \% \mathrm{~B} 1 \% 95 \% \mathrm{E} 7 \% 9$

A\%84\% E5\%8F\%B0\%Е7\%81\%A3\%E5\%AF\%B5\%E7 $\% 89 \%$ A9\%Е5\%B8\%82\%Е5\%A0\%B4/ 